\title{
Quedas em idosos: uma realidade complexa...
}

Me. Marcia Regina da Silva

Me. Rosane Paula Nierotka

Dra. Fátima Ferretti

Viver enquanto idoso é conviver com as mudanças produzidas pela passagem do tempo, que podem ser físicas, funcionais, sociais ou psíquicas. Dentre as alterações produzidas pelo avanço da idade, os distúrbios do equilíbrio são um dos principais fatores de instabilidade postural e risco de quedas em idosos, aumentando significativamente com a idade. Quanto a epidemiologia das quedas no Brasil há uma variação de ocorrência do evento em 12 meses, entre 10,7 e $59,3 \%$ da população, com média de $33,24 \%$ $( \pm 12,84)$, sendo o domicílio e no período diurno o cenário mais frequente para esses acidentes, e as consequências mais comuns são as fraturas ${ }^{1}$.

Outro fator importante quando se reflete sobre o impacto das quedas na saúde do idoso, é o maior índice de internação em função das intercorrências produzidas pelas quedas. Nas últimas décadas tivemos um aumento de $1.000 \%$ das taxas de internação por quedas, passando de 2,58 internações/10.000 idosos em 1996 para 41,37 internações/10.000 idosos em 2012, e de 300\% na mortalidade, de 1,25 para $3,75 / 10.000$ idosos em 2012, sendo que as taxas foram maiores para 0 sexo masculino ${ }^{2}$. Ainda, as quedas aumentam significativamente as taxas de morbidade/mortalidade e contribuem para a imobilidade, hospitalização e prematura institucionalização de idosos ${ }^{3,4}$.

As quedas são resultado da interação dos fatores de risco intrínsecos (situação nutricional, déficit vitamínico, perda da acuidade visual, auditiva e do equilíbrio, diminuição da força muscular, especialmente de membros inferiores, alterações na marcha, entre outros fatores desencadeados pelo processo de envelhecimento) e extrínsecos (calçadas quebradas e irregulares, iluminação insuficiente, excesso de utensílios no domicílio, pisos escorregadios, tapetes, entre outros) ${ }^{2}$.

A maioria das quedas em idosos ocorre na locomoção, por tropeços ou escorregões. Os fatores de risco ambientais representam grande parte das quedas em idosos (20-58\%), relacionados principalmente às superfícies irregulares, molhadas e escorregadias, objetos/tapetes soltos e desniveis no chão ou degraus irregulares e que os idosos com maior capacidade física caem mais em ambientes externos e aqueles com algum comprometimento, em ambientes internos ${ }^{5}$.

Estudo que identificou as causas e consequências de quedas em 389 idosos em domicílio, por sexo e faixa etária, evidenciou uma média de 1,6 quedas por ano, sendo que idosos longevos sofreram mais quedas, em média 2,16 por ano. Esses acidentes geram lesões na maioria dos idosos, sendo mais frequentes as escoriações, seguidas de fratura. 0 banheiro foi o local do domicílio mais citado em ambos os sexos, e a queda está principalmente relacionada aos afazeres ${ }^{6}$.

Considerando esta realidade, há que se buscar estratégias que promovam a manutenção das condições físicas e funcionais dos idosos, buscando garantir que estes permaneçam independentes,

\section{Fisiß̌enectus}


autônomos, pelo maior tempo possível. Prevenir as quedas em idosos, perpassa pela necessidade de estruturar programas de prevenção, com orientações quanto aos riscos, bem como, pela oferta de diferentes programas de exercício físico com treino de equilíbrio, força e flexibilidade a fim de garantir as habilidades físicas e funcionais para essa população. Ainda, há necessidade de que os profissionais atuem de forma interdisciplinar e multiprofissional para qualificar e tornar as ações mais resolutivas.

\section{Referências}

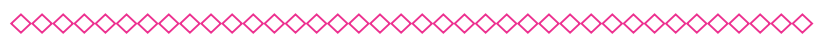

1. Leitão SM, Oliveira SC de, Rolimb LR, Carvalho RP de, Coelho Filho JM, Peixoto Junior AA. Epidemiologia das quedas entre idosos no Brasil: uma revisão integrativa de literatura. Geriatrics, Gerontology and Aging. Rio de Janeiro. 2018;12(3):172-79.

2. Abreu DROM, Novaes ES, Oliveira RR de, Mathias TA de F, Marcon SS. Internação e mortalidade por quedas em idosos no Brasil: análise de tendência. Ciência \& Saúde Coletiva. Rio de Janeiro. 2018;23(4):1131- 4.

3. Rubenstein LZ. Falls in older people: epidemiology, risk factors and strategies for prevention. Age and Ageing. London. 2006;35(Suppl. 2):37- 41.

4. Campbell AJ, Robertson MC. Implementation of multifactorial interventions for fall and fracture prevention. Age and Ageing. London. 2006;35(Suppl. 2):60-64.

5. Oliveira AS, Trevizan PF, Bestetti MLT, Melo Rc de. Fatores ambientais e risco de quedas em idosos: revisão sistemática. Revista Brasileira de Geriatria e Gerontologia. Rio de Janeiro. 2014; 17(3): 637-45.

6. Ferretti F, Lunardi D, Bruschi L. Causas e consequências de quedas de idosos em domicílio. Fisioterapia em Movimento. Curitiba. 2013;26(4):753-762. 